\title{
ARTIGOS
}

DOSSIÊ TERRITÓRIO, GÊNERO E INTERSECCIONALIDADES

\section{NARRAR A SERRA, IMAGINAR AS CIDADES: O RECURSO À FICÇÃO NA PESQUISA SÓCIO-ESPACIAL}

\author{
Camila Matos Fontenele* \\ *Universidade Federal de Minas Gerais, Programa de Pós-graduação em Arquitetura e Urbanismo, Belo \\ Horizonte, MG, Brasil
}

\section{Resumo}

Este trabalho tem origem no contato com moradoras idosas do Aglomerado da Serra, em Belo Horizonte, no âmbito de uma pesquisa internacional em rede. Naquele contexto, o material de diversas entrevistas foi desconsiderado por não responder diretamente às questões levantadas. Proponho aqui um retorno a esse material com o intuito de investigar a maneira como a força de trabalho desse grupo de mulheres foi fundamental, tanto na articulação da própria sobrevivência como na formação daquele território. Em primeiro lugar, abordo a natureza de ficção presente nas narrativas das idosas como possibilidade de fabulação sobre a vivência delas na cidade e a prospecção de futuro. Sugiro que a ficção também integra aquelas narrativas socialmente legitimadas enquanto "verdade", como é o caso da história oficial e do discurso das ciências. Nesse sentido, a ficção emerge como importante ferramenta no que se refere à autofabulação para as interlocutoras e ao questionamento e ao tensionamento do lugar de legitimidade dos discursos oficiais.

Palavras-chave

Ficção; Produção do Espaço; Pesquisas Sócio-espaciais; Gênero; Idosas. 


\title{
ARTICLES
}

DOSSIER TERRITORY, GENDER AND INTERSECTIONALITIES

\section{NARRATING SERRA, IMAGINING CITIES: THE USE OF FICTION IN SOCIO-SPATIAL RESEARCH}

\author{
Camila Matos Fontenele* \\ *Universidade Federal de Minas Gerais, Programa de Pós-graduação em Arquitetura e Urbanismo, Belo \\ Horizonte, MG, Brazil
}

\begin{abstract}
This work studies a series of interviews with elderly women who live at Aglomerado da Serra, in Belo Horizonte. Those interviews were carried out on June 2017, within the scope of an international network research whose methods turned out to be insufficient to deal with the complexity of narratives of the elderly women. Firstly, the nature of fiction present in the narratives of the elderly women is considered as a possibility of self-fabulation about their own experience in the city and as a tool to imagine the future. Then, I suggest that fiction is also part of those narratives which are socially legitimized as "truth", as it is the case with official history and the discourses of sciences. In this sense, fiction emerges as an important tool for self-fabulation, and for questioning and deconstructing the status of "truth" inherent in official discourse.
\end{abstract}

Keywords

Fiction; Space Production; Socio-Spatial Research; Gender; Elderly. 


\title{
NARRAR A SERRA, IMAGINAR AS CIDADES: 0 RECURSO À FICÇÃ́O NA PESQUISA SÓCIO-ESPACIAL'
}

\author{
Camila Matos Fontenele
}

\section{Introdução}

Em 2017, participei de uma pesquisa em rede, em Belo Horizonte, como pesquisadora assistente em uma colaboração internacional que tinha como objetivo entender em que condições viviam as pessoas idosas em grandes centros urbanos. A pesquisa em campo consistia na aplicação de diversos tipos de entrevista com pessoas idosas moradoras de diferentes regiões das cidades que a sediavam. Entretanto, o método de elaboração do material seguia uma estrutura rígida e definida verticalmente, de maneira que havia pouca margem de negociação em relação à forma como as entrevistas seriam analisadas. Por esse motivo, acabou-se por gerar um grande volume daquilo que eu viria a chamar de "resíduos narrativos", ou seja, materiais completos de entrevistas que foram desconsiderados por não responderem diretamente às questões elaboradas em laboratório pela coordenação geral da pesquisa - da qual a equipe de Belo Horizonte não fazia parte.

Foi em decorrência de um incômodo com esse modo de analisar e sistematizar o registro dessas entrevistas que dei início a uma pesquisa que veio a se tornar o tema do meu doutorado em Arquitetura e Urbanismo. Resolvi, portanto, seguir em contato com três entrevistadas, mulheres idosas moradoras do Aglomerado da Serra e, além de revisitar o material gravado, realizar novas entrevistas, com o objetivo de trazer para a discussão aquilo que eu acreditava ser o mais valioso naqueles registros - a narrativa de suas histórias de vida, de suas experiências cotidianas - e entender o que isso revelava sobre a construção daquele espaço. Este artigo resulta dessa pesquisa de doutorado.

1. O presente trabalho foi realizado com o apoio da Coordenação de Aperfeiçoamento de Pessoal de Nível Superior - Brasil (Capes) - Código de financiamento 001. 
A partir daí, uma série de desafios se desenhava, como o de narrar modos de vida que escapam à lógica da chamada cidade formal e do trabalho produtivo capitalista. Estar à margem do capitalismo coloca aquelas mulheres em uma posição de muitos atravessamentos em relação àquilo que a academia entende por trabalho produtivo e reprodutivo. Nesse lugar de fronteiras borradas, elas conseguiram articular a própria sobrevivência por meio de um acúmulo de saberes e funções ligados à garantia de recursos básicos e ao cuidado consigo, com a família e com a vizinhança. A comunidade se formava à medida que, para enfrentar a situação de extrema precariedade à qual estavam submetidas, era preciso inventar formas de colaboração e cooperação para além dos modos de vida burgueses propagados nos discursos oficiais sobre a vida na cidade dita formal.

Conforma-se aí uma situação complexa em que uma série de questões se atravessam de maneira interseccional e impactam a existência delas: trata-se de mulheres idosas, racializadas, periféricas, de baixa renda e que tiveram pouco acesso à escolarização formal (nenhuma delas é alfabetizada), o que as localiza em relação a um sistema de opressões por gênero, idade, raça, localização geográfica e classe. $\mathrm{O}$ fato de estarem inseridas na lógica capitalista de maneira precária - ou perversa - exige delas uma capacidade de inventividade para além das regulações do Estado e das práticas previstas na cidade formal. Na mesma medida, é preciso um olhar sensível e implicado ao estudar seus modos de vida em sua complexidade.

Este trabalho abordará, em primeiro lugar, a questão da ficção como qualidade comum a toda narrativa e a maneira como é utilizada, com base no recurso aos arquivos, como ferramenta de naturalização de processos históricos nos discursos considerados oficiais. Em seguida, a qualidade de ficção é abordada como possibilidade de questionamento da história oficial por meio da ideia de fiç̧ão visionária (IMARISHA, 2016). Na sequência, formulo uma discussão a respeito da importância da imagem e da oralidade como formas de trabalhar narrativas desenvolvidas para além do registro do texto escrito, o que é de vital importância, sobretudo quando se trabalha com grupos sócio-espaciais não alfabetizados². Finalmente, é construída uma discussão sobre os modos de vida dessas mulheres ancorada em trechos de suas narrativas.

\footnotetext{
2. O termo sócio-espacial é utilizado aqui com hífen, como proposto por Marcelo Lopes de Souza (2013) e reiterado por Silke Kapp (2018, p. 223-224.), quando esta defende que um grupo sócio-espacial seria formado por pessoas que se relacionam entre si em um espaço que, por sua vez é constitutivo e constituído por esse grupo. Assim, "a articulação entre espaço e nexo social é necessária e dialética: necessária porque o grupo não existiria sem ela; dialética porque tensionada e sempre complexa”. O uso do hífen contrapõe-se à grafia socioespacial, que sugere um continuum automático entre os dois. SOUZA, M. L. de. Os conceitos fundamentais da pesquisa sócio-espacial. Rio de Janeiro: Bertrand Brasil, 2013. KAPP, S. Grupos sócio-espaciais ou a quem serve a assessoria técnica. Revista Brasileira de Estudos Urbanos e Regionais, São Paulo, v. 20, n. 2, p. 221-236, 2018.
} 
1. Ficção

1.1 Narrar a cidade

O gesto de narrar dá significado às experiências. Antes dele, os acontecimentos não são mais que um emaranhado de eventos sobrepostos no espaço e no tempo. Narrar é, de algum modo, organizar sequencial e artificialmente esses eventos diante da impossibilidade de total precisão ou objetividade em relação a eles. Defendo, portanto, que a ficção é, em alguma medida, uma qualidade presente em toda narrativa, pois essa organização artificial depende do poder de fabulação de quem narra. Para elaborar narrativas, é preciso reconstruir cenários, descrever personagens, preencher vazios e ordenar os fatos. A objetividade, ainda que esteja no horizonte, resulta sempre inalcançável em sua completude.

Neste sentido, fabular é uma forma de tomar poder sobre si e sobre o mundo exterior, ao construir, a respeito dos acontecimentos, uma ou diversas narrativas. É, também, uma ferramenta importante para contestar aquelas narrativas que se afirmam como verdade oficial dos fatos, ou seja, que, ao se afirmarem como verdade única, destituem de legitimidade as narrativas dissidentes e usurpam de quem as narra o poder de fabulação.

O poder de narrar e de ter suas narrativas legitimadas tem sido, historicamente, objeto de disputa entrelaçado às lutas por território e pela produção do espaço, de maneira geral. Dito de outra forma, as disputas pela produção do espaço apresentam uma dimensão discursiva e envolvem sempre, em alguma medida, a luta pela visibilidade das narrativas sobre o espaço. Assim é que os processos históricos são artificialmente naturalizados para preservarem a aparência de verdade.

Na construção da naturalização dos processos históricos, são mobilizados diferentes materiais que registram e legitimam os acontecimentos e que são submetidos a um processo de seleção, descontextualização e recontextualização. Aqueles materiais escolhidos adquirem então a qualidade de arquivo. $O$ filósofo camaronês Achille Mbembe (2002) aprofunda a discussão a respeito do arquivo.

Institucionalmente, o arquivo funciona como uma plataforma onde se armazena o conhecimento de determinada sociedade sobre si mesma e sobre o mundo. De acordo com Mbembe (2002), o arquivo cumpre uma função dúbia no que concerne ao poder do Estado: por um lado, compõe e empresta credibilidade à história oficial e, por outro, se revisitado, pode fornecer as bases para o questionamento dessa história e, consequentemente, desestabilizar esse poder e animar a destituição de lideranças. Ou seja, o arquivo ordena a sociedade na mesma medida em que encarna uma ameaça a essa mesma ordem, diante da possibilidade de ser reorganizado e reinterpretado. Segundo Mbembe (2002, p. 21; tradução da autora): 
Ele [o arquivo] é a prova de que uma vida realmente existiu, de que algo realmente aconteceu, o relato de algo que pode ser construído. O destino final do arquivo, contudo, está sempre situado fora de sua materialidade, na história que ele possibilita. [...] Nenhum arquivo pode ser o repositório da história inteira de uma sociedade, de tudo o que aconteceu com aquela sociedade. Através de documentos arquivados, nos deparamos com porções de tempo a serem montadas, com fragmentos de vida a serem organizados, um após o outro, na tentativa de formular uma história cuja coerência advém da habilidade de forjar conexões entre o início e o fim.

Mbembe (2002) aborda ainda o arquivo por meio da metáfora da morte. Essa relação com a morte se dá no sentido em que os eventos arquivados aconteceram no passado, portanto, estariam supostamente encerrados, com participantes que muitas vezes já morreram. $\mathrm{O}$ arquivamento dos documentos e objetos que atestam a existência desses eventos, bem como a forma como se efetivaram, é uma maneira de encerrar o caso e possíveis contestações a seu respeito. Ou seja, a morte, em sua qualidade de evento absoluto, opera o disciplinamento do arquivo e impede que seus "fantasmas" voltem para assombrar o presente, o mundo dos vivos.

Esse disciplinamento é empreendido pelo Estado com o objetivo de transformar o passado em um território inócuo e, dessa maneira, liberar-se de suas dívidas históricas com aquelas populações oprimidas e ocultadas durante esse processo.

Em contraposição à tradição da historiografia oficial, a escritora e educadora estadunidense Walidah Imarisha (2016) define a ficção visionária como categoria literária que, assim como a historiografia clássica, apropria-se de documentos, fontes oficiais e eventos históricos, mas que, ao contrário daquela, assume e explicita o caráter ficcional das narrativas que produz. A ficção visionária costuma utilizar também recursos narrativos frequentemente presentes em ficções científicas, como viagem no tempo, coexistência entre humanos e seres sobrenaturais ou, ainda, viagens entre diferentes mundos.

Para Imarisha (2016), a ficção visionária procura superar um estado de coisas aparentemente insuperável com as ferramentas conhecidas e emprega recursos percebidos como impossíveis no mundo tal como o conhecemos para imaginar futuros e realidades alternativas, sobretudo em contextos de luta contra opressões históricas e violência do Estado, e por justiça social de modo geral. Imarisha (2016) afirma:

Apesar de nossa habilidade para analisar e criticar, a esquerda se enraizou naquilo que é. Nós frequentemente esquecemos de vislumbrar aquilo que pode vir a ser. Esquecemos de escavar o passado em busca de soluções que nos mostrem como podemos existir de outras 
formas no futuro. Por isso acredito que nossos movimentos por justiça precisam desesperadamente da ficção científica. [...] Toda articulação política é ficção científica.

Imarisha (2016) aponta possibilidades de "reescrever o futuro" com o propósito de construir uma capacidade de imaginá-lo para além das possibilidades postas no presente. Essa capacidade se revela fundamental para a sobrevivência de povos historicamente oprimidos, em especial quando essas opressões se manifestam de maneira interseccional, como é o caso de mulheres, pessoas racializadas e dissidentes em suas identidades de gênero ou em suas orientações sexuais - em suma, de todos os modos de vida que divergem da identidade do homem cisgênero, branco e heterossexual.

A importância das narrativas enquanto ferramenta para o pensamento crítico ou para lutas urbanas tem sido abordada por uma diversidade de autoras. Especificamente no que toca à discussão sobre gênero, racialidade e interseccionalidades, destaco a obra de pensadoras como a brasileira Gabriela Leandro Pereira (2015), a estadunidense Saidiya Hartman (2019) e a australiana Leonie Sandercock (2005). Com base em diferentes dispositivos, o trabalho dessas autoras compõe um panorama sobre diferentes modos de narrar a cidade.

Pereira (2015), no trabalho intitulado Corpo, discurso e território: a cidade em disputa nas dobras da narrativa de Carolina Maria de Jesus, propõe-se "deslizar por entre a narrativa da escritora Carolina Maria de Jesus (1914-1977) e suas dobras, para tensionar os lugares de disputa, conflito e criação que atravessam e se (re) produzem na cidade" (PEREIRA, 2015, p. 8). A autora tece uma discussão sobre a relação entre o lugar social e geográfico (território) dos sujeitos em sua dimensão corporal e a produção discursiva que articulam sobre si mesmos, sobre o Outro e sobre as cidades. Baseando-se nisso, Pereira toca questões acerca das políticas de visibilidade das narrativas produzidas - em diferentes temporalidades - desde lugares e corpos-sujeitos historicamente marginalizados. É aí que a obra e a vida de Carolina Maria de Jesus atravessam e se atualizam na experiência de corpos-sujeitos de outros tempos³. De acordo com Pereira (2015, p. 192):

Em sua corpografia, Carolina experiencia e registra a cidade atravessada por todas essas [outras pessoas]. Ela, essa cidade, é o nó que

\footnotetext{
3. Especificamente no trabalho citado, Pereira tece atravessamentos - que se dão na espiral-do-tempo - entre a obra de Carolina Maria de Jesus e as histórias da diretora de cinema Yasmin Thayná, do escritor Marcus Faustini, da escritora Conceição Evaristo e das mulheres que compõem o movimento Mães de Maio - mães, familiares e amigas das pessoas assassinadas durante os "crimes de maio de 2006” em São Paulo.
} 
amarra as questões trabalhadas nessa tese. É nela que as dimensões corpo e discurso atravessam o território, o afetam e são afetadas.

A australiana Leonie Sandercock (2005) oferece uma colaboração fundamental para essa discussão sobre narrativas, ficção e a produção do espaço, ao defender que as narrativas são uma forma ancestral de representar as cidades e suas dinâmicas irrepresentáveis. Na sua experiência em diversos projetos de planejamento urbano, Sandercock identificou que, assim como os indivíduos, há grupos e comunidades que costumam estruturar sua memória coletiva em torno de uma história central que tende a ser constantemente recontada e reencenada. De acordo com a autora, por meio de práticas de planejamento urbano, seria possível transformar tais histórias em um processo de cura. No artigo "Debatendo o preconceito: a importância das histórias e sua narração na prática do planejamento" (2005), Sandercock (2005) sistematiza uma série de estruturas de enredo 4 nas quais a maioria das histórias se alicerça, para em seguida nos apresentar uma variedade de experiências em planejamento urbano em que o trabalho com as narrativas - tanto no que diz respeito à contação de histórias propriamente dita como ao fomento a espaços para contar histórias - foi fundamental para a articulação entre os diferentes agentes.

Defendo tanto uma abordagem criativa quanto uma abordagem crítica de histórias e narração de histórias. [...] A utilização de histórias na prática do planejamento deve estar aberta ao mesmo processo de análise crítica, inclusive à vigilância quanto aos modos como o poder determina quais as histórias a serem contadas, ouvidas e a ter relevância.

[...]

Se quisermos saber como podemos coexistir uns com outros, com todas as nossas diferenças, à medida que as cidades se tornam mais multiétnicas e multiculturais, a necessidade de travar um diálogo com estranhos deve tornar-se uma arte urbana, e não apenas uma arte do planejador. Essa "mais antiga das artes" começa com o compartilhamento de histórias e move-se em direção à formação de novas histórias coletivas. (SANDERCOCK, 2005, p. 23-24)

No trabalho Wayward lives, beautiful experiments: intimate stories of social upheaval [em tradução aproximada, Vidas rebeldes, belos experimentos: histórias

4. Entre as estruturas de enredo citadas por Sandercock (2005) estão o conto do herói, o conto do pioneiro, contos sobre a "idade de ouro perdida", o estranho que chega a uma cidade, o jovem que sai de casa para encontrar a si mesmo ou para criar seu lugar no mundo. A autora defende que boa parte das narrativas sobre cidades, sobre comunidades ou mesmo aquelas tecidas por seus moradores sobre si mesmos tem como ponto de partida essa gama de estruturas de enredo. 
íntimas sobre insurgência social] (2019), a estadunidense Saidiya Hartman constrói uma narrativa protagonizada por jovens mulheres que teriam vivido em lugares periféricos dos Estados Unidos, como becos na Filadélfia, ruas no Harlem, em Nova Iorque, ou mesmo em reformatórios femininos e em estúdios de artistas periféricas. Para elaborar essa ficção, Hartman parte de uma série de documentos provenientes das mais diversas fontes, como fotografias de favelas, entrevistas com psiquiatras, arquivos de casos de prisão - em todos eles, essas jovens são retratadas como causadoras de problemas. Dessa maneira, a autora parte dos "furos" dos registros oficiais com o intuito de completá-los e assim construir uma contranarrativa que as represente em sua complexidade, para além do julgamento e das classificações oficiais. Em suas práticas cotidianas, elas experimentavam intimamente modos de vida outros para além do - e em recusa ativa ao - controle do Estado e das instituições.

Elaborei uma contranarrativa liberada do julgamento e da classificação que sujeitava jovens negras à vigilância, prisão, punição e confinamento, e que oferece um relato sobre belos experimentos - que fazem da vida uma arte - realizados por aquelas que eram muitas vezes descritas como promíscuas, imprudentes, selvagens e rebeldes. 0 esforço é recuperar o terreno insurgente dessas vidas; para exumar a rebelião aberta do arquivo, para desamarrar a teimosia, a recusa, a ajuda mútua e o amor livre de sua identificação com as ideias de desvio, criminalidade e patologia; para afirmar a maternidade livre (escolha reprodutiva), a intimidade fora da instituição do casamento e as paixões queer e fora da lei; e para iluminar a imaginação radical e a anarquia cotidiana de meninas de cor comuns, que não só foram esquecidas, como são quase inimagináveis. (HARTMAN, 2019, p. 6-7; tradução da autora.)

\subsection{Discurso e linguagem}

O pensamento de Denise Ferreira da Silva (2016) é valioso porque questiona os discursos oficiais, sobretudo aqueles relacionados às ciências. Essa filósofa brasileira localiza na origem do pensamento cartesiano o aspecto da separabilidade entre pares binários - por exemplo, entre corpo e mente, espaço e tempo, natureza e razão - como forma violenta de lidar com a diferença.

Ferreira da Silva (2016) sugere que a estrutura lógica do pensamento moderno inaugurado em Descartes lida com as diferenças culturais nos registros da separação e da dominação. Portanto, as ferramentas críticas produzidas no âmbito desse pensamento "não suportam a ideia de uma intervenção ético-política que reduza a capacidade da diferença cultural de produzir uma separação ética intransponível” (FERREIRA DA SILVA, 2016, p. 58). 
O que Descartes introduziu no século 17 foi uma separação entre a mente e o corpo segundo a qual a mente humana, devido à sua natureza formal, também adquire a capacidade de determinar tanto a verdade sobre o corpo do homem, quanto sobre tudo aquilo que compartilha de seus atributos formais, como solidez, extensão e peso. (FERREIRA DA SILVA, 2016, p. 59-60)

É na base do pensamento cartesiano moderno que se funda a oposição binária que legitima o domínio do pensamento científico produzido na academia - tradicionalmente masculino, branco e heterossexual - sobre as modalidades de pensamento produzidas no interior de outras matrizes de saber, como é o caso dos povos tradicionais ou de moradoras de comunidades periféricas.

O compromisso com a produção de outras ficções deve ser, antes de tudo, o compromisso em construir uma ponte, um diálogo possível com os corpos historicamente apartados da academia, não apenas em uma prática de apropriação dos seus saberes, mas de partilha de privilégios. Este é um compromisso que se firma com a devolução dos recursos que os corpos historicamente predominantes na academia - uma elite financeira e cultural predominantemente branca - têm expropriado dos corpos periféricos, subalternizados e preponderantemente racializados, seja com a exploração de sua força de trabalho, em uma história de séculos de naturalização do trabalho escravo que se atualiza e se materializa no capitalismo global contemporâneo, seja com a invasão de suas terras e a extração de seus recursos naturais.

Emerge aí um imbróglio crucial no campo da linguagem: a academia opera fundamentalmente por meio do texto escrito e, ao lidar com grupos sócio-espaciais historicamente subalternizados, estará lidando, em muitos momentos, com pessoas para as quais o texto escrito não é o principal meio de estruturação do pensamento. Nenhuma das três idosas que atuaram como interlocutoras nesta pesquisa é alfabetizada. Isso foi identificado na experiência com as mulheres idosas moradoras do Aglomerado da Serra, mas não é, de maneira alguma, exclusividade desse grupo específico, embora seja mais recorrente em grupos sócio-espaciais de formação semelhante (mulheres idosas, racializadas, em sua maioria migrantes, habitantes de periferias urbanas). Fatores como faixa etária, renda, racialização e localização geográfica são marcadores importantes para compreender o estado da não alfabetização no Brasil5.

\footnotetext{
5. De acordo com a Pesquisa Nacional por Amostra de Domicílio (PNAD) Contínua de 2018, àquela altura, a taxa de analfabetismo no Brasil era de 6,8\% entre pessoas com quinze anos de idade ou mais e de $18,6 \%$ entre aqueles com sessenta anos de idade ou mais.
} 
A professora Leda Maria Martins (2003) pontua que o modelo eurocentrado predominante na produção, no armazenamento e na partilha do conhecimento acadêmico está prioritariamente restrito ao domínio da visão, uma vez que opera principalmente por meio da palavra escrita. Deste modo, para Martins (2003, p. 64), todas as outras formas de pensar são deslocadas para o lugar do ex-ótico, ou seja, daquilo que não pode ser alcançado pela visão:

Tudo que escapa, pois, à apreensão do olhar, princípio privilegiado de cognição, ou que nele não se circunscreve, nos é ex-ótico, ou seja, fora de nosso campo de percepção, distante de nossa ótica de compreensão, exilado e alijado de nossa contemplação, de nossos saberes. E somos férteis em nossos recursos de resguardo dessa memória [visual]: os nossos livros, arquivos, bibliotecas, monumentos, parques temáticos e, mais recentemente, os avanços tecnológicos, como hardwares e softwares cada vez mais sofisticados.

Para além de apontar a não alfabetização como um problema social, percebo a urgência em aprofundar essa questão para construir um panorama mais complexo dentro do qual ela se manifesta. O nível de escolarização no Brasil é um indicador diretamente relacionado ao nível de renda de seus grupos sociais. Em outras palavras, o tempo a que uma pessoa foi submetida à educação formal é condicionante para a sua situação de renda ${ }^{6}$.

Refletir sobre esse dado explicita, por um lado, a necessidade premente de ampliar o acesso à educação, à democratização do ensino e, em última instância, à ampliação das condições de mobilidade social rumo àquelas populações historicamente subalternizadas e empobrecidas.

Por outro lado, também é urgente promover o reconhecimento daqueles saberes não advindos nem inseridos em uma lógica tradicional de escolarização - a saber, construída nos moldes do saber científico ocidental moderno -, igualmente válidos e valiosos. Incorporar outras formas de elaborar o pensamento, mas, para além disso, criar condições para a legitimação de saberes historicamente desconsiderados, ainda que válidos, é um compromisso primordial da academia para com as populações com quem constantemente tem trabalhado, sobretudo no campo das ciências sociais aplicadas ${ }^{7}$.

\footnotetext{
6. Os economistas brasileiros Daniel Duque e Carlos Góes (2018) apontam essa relação entre escolarização e renda no Brasil, ao definir uma fórmula matemática para analisar dados divulgados pela PNAD Contínua. DUQUE, D.; GÓES, C. Universidade pública e desigualdade de renda no Brasil: fatos, dados e soluções. In: SACHSIDA, A. (org.). Políticas públicas: avaliando mais de meio trilhão de reais em gastos públicos. Brasília, DF: Ipea, 2018. v. 1, p. 531-554.

7. No campo da arquitetura, isso é muito presente quando se trabalha com grupos sócio-espaciais que estão fora da definição de cidade formal, como as favelas e as ocupações urbanas.
} 


\section{Imagem}

A imagem, em princípio, não requer o domínio de um código específico para ser decifrada, como é o caso da escrita. Por isso mesmo, parece se tratar de uma interface possível e especialmente interessante, quer dizer, uma linguagem comum capaz de atravessar "diferentes mundos". A imagem aparece aqui como meio de expressão de pensamento, registro de memória e dispositivo para guardar e contar histórias, passível de ser operado tanto por pessoas acadêmicas como pelas não acadêmicas, uma vez que, para ler imagens, não é preciso saber ler textos escritos.

O filósofo tcheco-brasileiro Vilém Flusser (1985) identifica no advento da fotografia o principal marco na transição da era do texto para a era das imagens técnicas (produzidas por meio de aparelhos), ou seja, do paradigma que identifica como histórico, quando o texto escrito linear e sequencialmente é o principal meio de articulação do pensamento e da comunicação; para aquele momento que identifica como pós-histórico, em que as imagens técnicas são dominantes para a sociedade ocidental.

Flusser (2002) aborda as noções de fato e ficção na sociedade ocidental, quando identifica a crise inerente ao momento pós-histórico. De acordo com seu argumento, nesta sociedade convivem o mundo daqueles que dominam a palavra escrita e articulam o pensamento segundo uma lógica linear, sequencial e histórica (a chamada "elite cultural") e o mundo daqueles que não a dominam e, dessa maneira, se mantêm restritos às imagens técnicas e articulam o pensamento pautados em uma lógica superficial, não sequencial e pós-histórica (a chamada "sociedade de massa”).

Apesar de a lógica cartesiana impor uma separação hierárquica entre essas duas formas de perceber e pensar o mundo, é importante destacar que Flusser (2002) propõe desconstruir essa hierarquização, quando sugere que ambos os paradigmas se encontram em crise no atual momento histórico.

A crise se desenrola à medida que o texto, empobrecido pela sua objetividade inerente, perde crescentemente o contato com os acontecimentos que pretendia representar, enquanto as imagens técnicas, por seu turno, passam a ser produzidas de maneira cada vez mais verossímil, quer dizer, aparentam cada vez mais ser verdadeiras, ao ponto de se descolarem radicalmente dos acontecimentos que pretendiam representar e terminam por perder também a relação com eles. Flusser (2002, p. 29; tradução da autora) assevera:

Tanto para a elite como para aqueles que participam quase que unicamente da cultura de massas, chegar aos fatos é um problema, mas esse problema é diferente em cada um dos grupos. Para a elite, o problema é que, quanto mais objetiva e clara se torna a fiç̧ão linear, 
mais ela se torna pobre, pois tende a perder o contato com os fatos que busca representar (todo o sentido). Portanto, as mensagens da ficção linear não se adequam mais satisfatoriamente à experiência imediata que ainda temos do mundo. Já no caso da cultura de massas, o problema é que, quanto mais tecnicamente perfeitas as imagens se tornam, mais ricas elas ficam e mais completamente substituem os fatos que buscavam representar originalmente. Portanto, os fatos não são mais necessários; as imagens bastam por si mesmas e, assim, perdem todo o seu significado original. Elas não precisam mais ser adequadas à experiência imediata do mundo e essa experiência é, então, abandonada. Em outras palavras, o mundo da ficção linear, o mundo da elite, está revelando cada vez mais o seu caráter meramente conceitual e fictício - enquanto o mundo da ficção superficial, o mundo das massas, tem mascarado sua qualidade ficcional cada vez melhor. Não podemos mais retornar do pensamento conceitual aos fatos por falta de adequação, e não podemos mais retornar do pensamento imagético aos fatos por falta de critérios que nos permitam distinguir entre acontecimento e imagem. Em ambos os casos, perdemos nosso senso de "realidade" e, assim, nos tornamos alienados.

Flusser (2002) aponta como saída possível para essa crise o desenvolvimento das capacidades dos espectadores, ou seja, daqueles que lidam com imagens técnicas - na sociedade ocidental contemporânea, é possível dizer de maneira genérica que esse é o caso da maior parte das pessoas -, de atuarem ativamente na produção delas; falamos aqui da interferência consciente nas estruturas que as geram. Em outras palavras, a participação na história, não simplesmente como personagens em uma trama, mas sim como jogadores que se apropriam dos meios de produção das imagens e que conseguem, de fato, jogar com elas. Para que isso se concretizasse, seria preciso entendê-las em sua estrutura, interferir nessa estrutura e desenvolver, desse modo, a capacidade de interpretá-las e reinterpretá-las.

As ferramentas conceituais emprestadas por Flusser são muito interessantes de um ponto de vista analítico, em que "sociedade de massas" e "elite cultural" aparecem como polos apartados e distantes. Na vida cotidiana e na experiência com o real, essas definições se manifestam de maneira entrecruzada e seus limites não são tão rígidos como no mundo da teoria. Os desafios que efetivamente se apresentam no trabalho com as imagens no contexto do recurso à ficção como ferramenta de pesquisa sócio-espacial são, por um lado, a elaboração de critérios que orientem a sua observação no tocante ao entendimento de que modo e por que foram produzidas - crítica das representações oficiais -; e, por outro, consistem na experimentação do uso das imagens técnicas e de sua qualidade ficcional como forma de especular sobre outros mundos possíveis. 


\section{Oralidade}

Embora esteja pautada na palavra - do mesmo modo como ocorre com o texto escrito -, a oralidade articula saberes que são produzidos, guardados e transmitidos por intermédio do corpo, da presença e da memória. Neste sentido, para aprofundar essa discussão, é interessante evocar sua dimensão performática, ou seja, sua dimensão como expressão incorporada, personificada e coletiva.

A professora estadunidense Diana Taylor (2013) faz uso das categorias de arquivo e repertório para abordar as diferenças entre o pensamento articulado prioritariamente por meio do corpo e o pensamento que se articula apoiado em arquivos, dos quais faz parte o texto escrito. Por operar como evidência material fragmentada e incompleta de determinado evento, o arquivo carrega em si sempre uma lacuna, há sempre algo que lhe escapa, seja por tratar-se de resquícios não considerados relevantes a ponto de se tornarem arquivos - e isso decerto envolve uma série de decisões politicamente implicadas -, seja por tratar-se de evidências cuja natureza mesma não é arquivável. Segundo Taylor (2013), repertório seria o conjunto de práticas, expressões e manifestações não passíveis de serem arquivadas, como é o caso da oralidade.

O repertório requer presença - pessoas participam da produção e reprodução do conhecimento ao "estar lá", sendo parte da transmissão. Em oposição aos objetos no arquivo, supostamente estáveis, as ações do repertório não permanecem as mesmas. O repertório ao mesmo tempo guarda e transforma as coreografias de sentido. (TAYLOR, 2013, p. 50)

Ainda de acordo com essa autora, "a memória arquival trabalha a distância, acima do tempo e do espaço” (2013, p. 49), enquanto a expressão incorporada da memória ou do pensamento, ou seja, o repertório, se dá em tempo real, de maneira presentificada e coletivizada, razão pela qual não pode ser capturada pelo arquivo. Discutir as distinções e as aproximações entre o pensamento que se articula via texto escrito e aquele que se articula via oralidade é, portanto, uma forma de abordar também as distinções e as aproximações entre memória e história ou, para usar os conceitos propostos por Taylor, entre repertório e arquivo (Figura 1). 


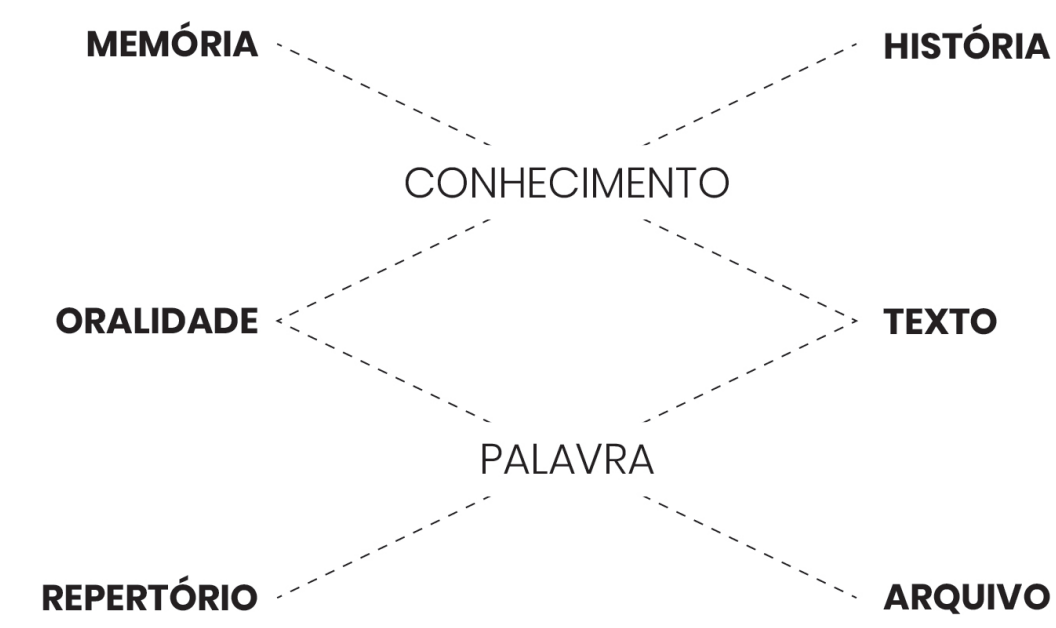

Figura 1. Esquema de conceitos que orbitam o tema da oralidade Fonte: Elaborado pela autora.

O historiador francês Pierre Nora (1993) propõe uma aproximação semelhante, ao estabelecer distinção entre aquilo que seria "uma memória verdadeira, hoje abrigada no gesto e no hábito, nos ofícios onde se transmitem os saberes do silêncio, nos saberes do corpo, as memórias de impregnação” (NORA, 1993, p. 14), e o que considera ser memória arquivística, apoiada "inteiramente sobre o que há de mais preciso no traço, mais material no vestígio, mais concreto no registro, mais visível na imagem” (NORA, 1993, p. 14). Para esse autor, a história resulta da materialização da "memória viva e social" por meio do arquivo, ou seja, a memória arquivística é a memória viva transformada em história.

A oralidade, por seu turno, não carece de nenhuma plataforma de representação ou registro. Nesse sentido, constitui-se como aquilo que Leda Maria Martins (2003) identifica como gesto performático, cujo conteúdo, ao contrário do conhecimento arquivado, permanece no tempo na medida em que não pode, em si mesmo, permanecer em uma forma fixa. Permanece, assim, na impermanência, apenas no presente, apenas conforme é reencenada e, quando isso acontece, instaura sempre novos sentidos.

Existe ainda uma dimensão social da oralidade, uma vez que o conhecimento que ela incorpora é acessado por meio de um repertório de práticas presenciais e intrinsecamente coletivas. Para a performance da oralidade, é preciso que haja, no mesmo tempo e espaço, uma variedade de interlocutores. Seu conteúdo é reativado com a repetição de narrativas de tempos em tempos, através da fala. A dimensão social é, neste sentido, também, uma dimensão ritualística. Portanto, a oralidade 
não pode ser praticada individualmente, é indissociável de um corpo coletivo que a mantenha viva. Nora (1993, p. 9) assinala que:

\begin{abstract}
A memória é a vida, sempre carregada por grupos vivos e, nesse sentido, ela está em permanente evolução, aberta à dialética da lembrança e do esquecimento, inconsciente de suas deformações sucessivas, vulnerável a todos os usos e manipulações, suscetível de longas latências e de repentinas revitalizações. A história é a reconstrução sempre problemática e incompleta do que não existe mais. A memória é um fenômeno sempre atual, um elo vivido no eterno presente; a história, uma representação do passado.
\end{abstract}

A oralidade seria, desta maneira, uma via por meio da qual essa memória viva, impermanente, coletiva e social, ainda não transformada em história por meio do recurso ao arquivo, é reativada, presentificada e atualizada. O filósofo francês Michel De Certeau (1982) descreve a palavra escrita como ferramenta fundamental para a constituição de uma história supostamente "pura", verdadeira, fiel aos fatos e que, por isso mesmo, define o lugar de superioridade de quem a escreve. Nesse sentido, a escrita, como o arquivo, articula um jogo de poder que estabelece uma ordem de dominação daquelas sociedades "alfabetizadas" - consideradas civilizadas de acordo com o pensamento cartesiano - sobre aquelas "iletradas”, predominantemente orais - ditas selvagens.

A possibilidade de arquivamento erradica a condição de presentificação da memória em relação ao tempo e ao espaço, enquanto a oralidade é "a palavra que não vai longe e que não retém” (DE CERTEAU, 1982, p. 216). A memória pode, em decorrência de sua transformação em história, e por meio da autenticação possibilitada pelo arquivo, existir, em alguma medida, em descompasso com um corpo coletivo que a mantenha viva, porque pode, diferentemente da voz, vencer a distância e permanecer no tempo.

Finalmente, ao contrário da memória arquivística, "intensamente retiniana e poderosamente audiovisual" (NORA, 1993, p. 19), a oralidade independe de um engajamento visual. Mobiliza, por sua vez, aqueles aspectos ex-óticos da experiência com o real. Implica, desse modo, um engajamento do corpo em seus diferentes sentidos. De Certeau (1983, p. 230) afirma:

O olho está a serviço de uma "descoberta do mundo". É a cabeça de ponte de uma "curiosidade" enciclopédica que, no século XVI[,] "amontoa freneticamente" os materiais e estabelece assim "os fundamentos da ciência moderna". O raro, o estranho, o singular - objetos já colecionados pela atenção medieval - são apreendidos no "fervor" 
de uma ambição: "que nada permaneça estranho para o homem e que tudo se torne servidor dele".

Essa reflexão sobre a cultura oral, bem como o trabalho com as imagens, retorna quando me debruço sobre as narrativas das mulheres idosas do Aglomerado da Serra. A seguir, proponho uma análise que parte dos relatos das entrevistadas e das imagens realizadas à altura.

\section{Partir dos relatos}

Escolhi trabalhar com as narrativas de três mulheres cujos relatos foram selecionados dentre um universo de dezenove pessoas idosas, moradoras do Aglomerado da Serra, entrevistadas entre julho e setembro de 2017. Como mencionado anteriormente, o conteúdo dessas entrevistas fora utilizado como suporte para o preenchimento de questionários e para a extração de informações quantitativas, de modo que o que escapava às questões predeterminadas era descartado do projeto - como foram os áudios de todas as entrevistas. À altura, três métodos foram aplicados: o que eventualmente chamamos de entrevista estacionada, entrevista caminhada e diário fotográfico.

O diário fotográfico de Dalva ${ }^{8}$, uma das entrevistadas, tem uma particularidade interessante. Ela optou por tirar "fotos de fotos" e registrar o seu álbum de fotografias composto, principalmente, de registros feitos por Afonso Pimenta, reconhecido fotógrafo morador do Aglomerado da Serra desde a geração pioneira. O trabalho de Afonso Pimenta é estudado com frequência por pesquisadores dos campos da cidade, da imagem e da comunicação9 ${ }^{9}$ A informação sobre a autoria dessas fotografias do acervo de Dalva veio anos depois da pesquisa em rede, já no contexto da minha pesquisa de doutorado.

Em 2017, o primeiro contato entre as idosas e a equipe de pesquisa se deu durante uma entrevista no Centro de Referência em Assistência Social (Cras) da Vila Nossa Senhora de Fátima (entrevista estacionada). Em outro momento, fizemos uma entrevista enquanto caminhávamos do Cras até suas casas (entrevista caminhada) e, finalmente, as idosas ficavam com uma câmera cybershot por uma semana e registravam momentos, lugares e personagens do seu cotidiano (diário

\footnotetext{
8. Os nomes das entrevistadas foram alterados com o intuito de proteger sua identidade.

9. Atualmente, Pimenta faz parte do projeto Retratistas do Morro, coordenado pelo pesquisador Guilherme Cunha, por intermédio do qual esteve presente em diversas exposições em galerias e centros culturais pelo Brasil. A obra de Pimenta também foi publicada no número 14 da revista ZUM, do Instituto Moreira Salles. Um sumário visual dessa edição está disponível em: https://revistazum.com.br/ revista-zum-14/conheca-zum-14/. Acesso em: 5 jul. 2021.
} 
fotográfico). Após esse período, nós nos encontrávamos mais uma vez e uma nova entrevista era realizada.

Ao contrário de uma vida de ócio e descanso, como se costuma imaginar com respeito a pessoas idosas, em contextos de intensa vulnerabilidade sócio-espacial, há, na verdade, uma carga de trabalho multiplicada, já que as mulheres idosas precisam muitas vezes cuidar de si, de filhos, netos e bisnetos. Além disso, elas costumam ser responsáveis pela segurança financeira da família, em razão de, não raro, serem a única pessoa do núcleo familiar com uma renda fixa, advinda da aposentadoria que recebem. Adicionalmente, é comum que sejam também a única pessoa da família a ter imóvel próprio.

Uma parte imensa das carências estruturais em favelas, bem como das demandas fundamentais das grandes cidades, foi e ainda é suportada, amenizada e compensada pelo trabalho realizado pelas mulheres, hoje idosas, e que permanece invisibilizado. A divisão do trabalho por gênero impõe a elas todas as tarefas relacionadas à reprodução da força de trabalho. Entretanto, as fronteiras entre trabalho de reprodução e trabalho remunerado são borradas, indistintas, atravessadas. É comum, por exemplo, que algumas dessas mulheres tenham sido parceiras de agentes da prefeitura em projetos urbanísticos. Estar em contato com quem tomava as decisões não era exatamente um trabalho remunerado, tampouco era diretamente um trabalho de cuidado, mas uma forma de estar a par das políticas urbanas, e de representar algum tipo de influência aliada aos interesses da comunidade.

Esse é o caso de Dalva, que nos anos 1980 administrava um bar e restaurante (Figuras $2 \mathrm{e} 3$ ). Ela conta que chegava às $8 \mathrm{~h}$ no bar para preparar o almoço que serviria aos clientes e à própria família e saía às 3 h da manhã do dia seguinte, quando o estabelecimento encerrava as atividades. O tempo para descanso era mínimo, o que a forçava a tirar pequenos cochilos nas cadeiras do bar ao longo do dia. Além disso, ela frequentava, semanalmente, reuniões com agentes da prefeitura e chegava, inclusive, a ceder o espaço de sua casa para que ali se guardassem materiais de trabalho durante as obras na vizinhança.

Olha aí eu dormindo! Quando era quatro horas, que dava aquela vontade de dormir, eu tinha muito freguês, eles falavam comigo assim velha, senta lá, fica lá num cantinho pra poder vocề cochilar! Nós toma conta do balcão! Aqui é meu esposo. Ele põe o bichinho na cabeça. Ele tinha um bichinho, um macaquinho, aí ele colocava na cacunda e botava na cabeça ${ }^{10}$.

10. Diário fotográfico de Dalva, em 21 de junho de 2017. 
Há ainda outros aspectos comuns às experiências de Dalva, Marta e Irene, como o fato de as três terem migrado para Belo Horizonte em busca de melhores oportunidades de trabalho e moradia"1. Também têm em comum o fato de terem vivido situações de exploração por trabalho infantil, de não terem sido alfabetizadas e de serem, as três, mulheres negras.

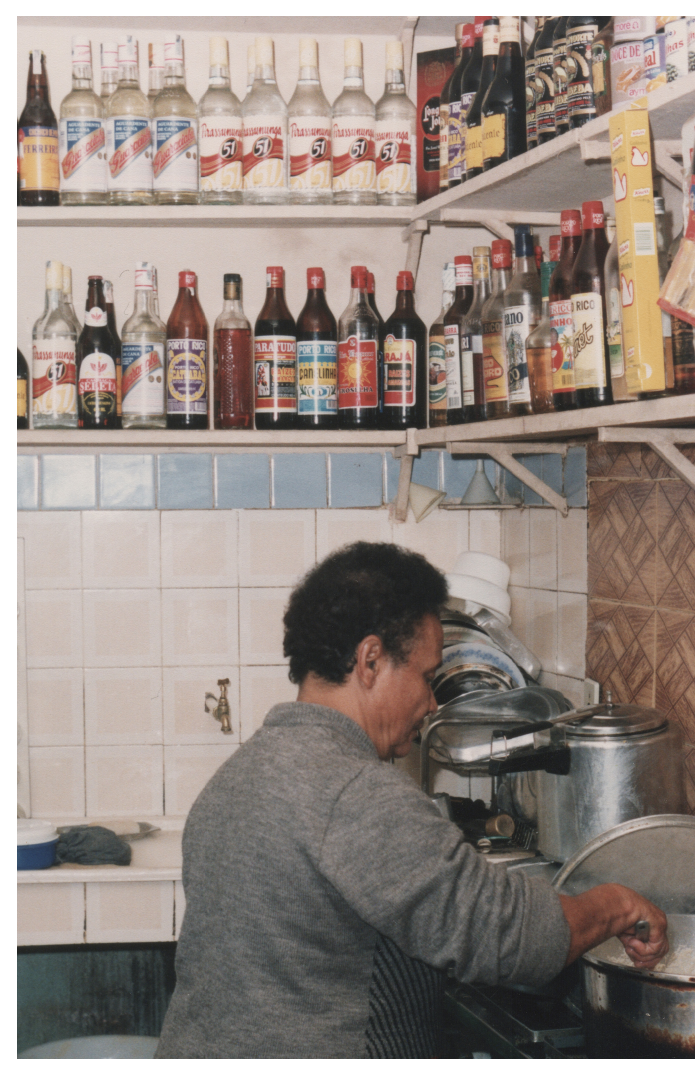

Figura 2. Foto (a) do acervo de Dalva

Fonte: Acervo pessoal de Dalva. Fotografias de Afonso Pimenta digitalizadas pela autora em 2020.

11. Dalva nasceu em um distrito da zona rural da Bahia, próximo a Porto Seguro; Irene nasceu no município mineiro de Santa Efigênia de Minas, e Marta nasceu em Coimbra, também em Minas Gerais. 


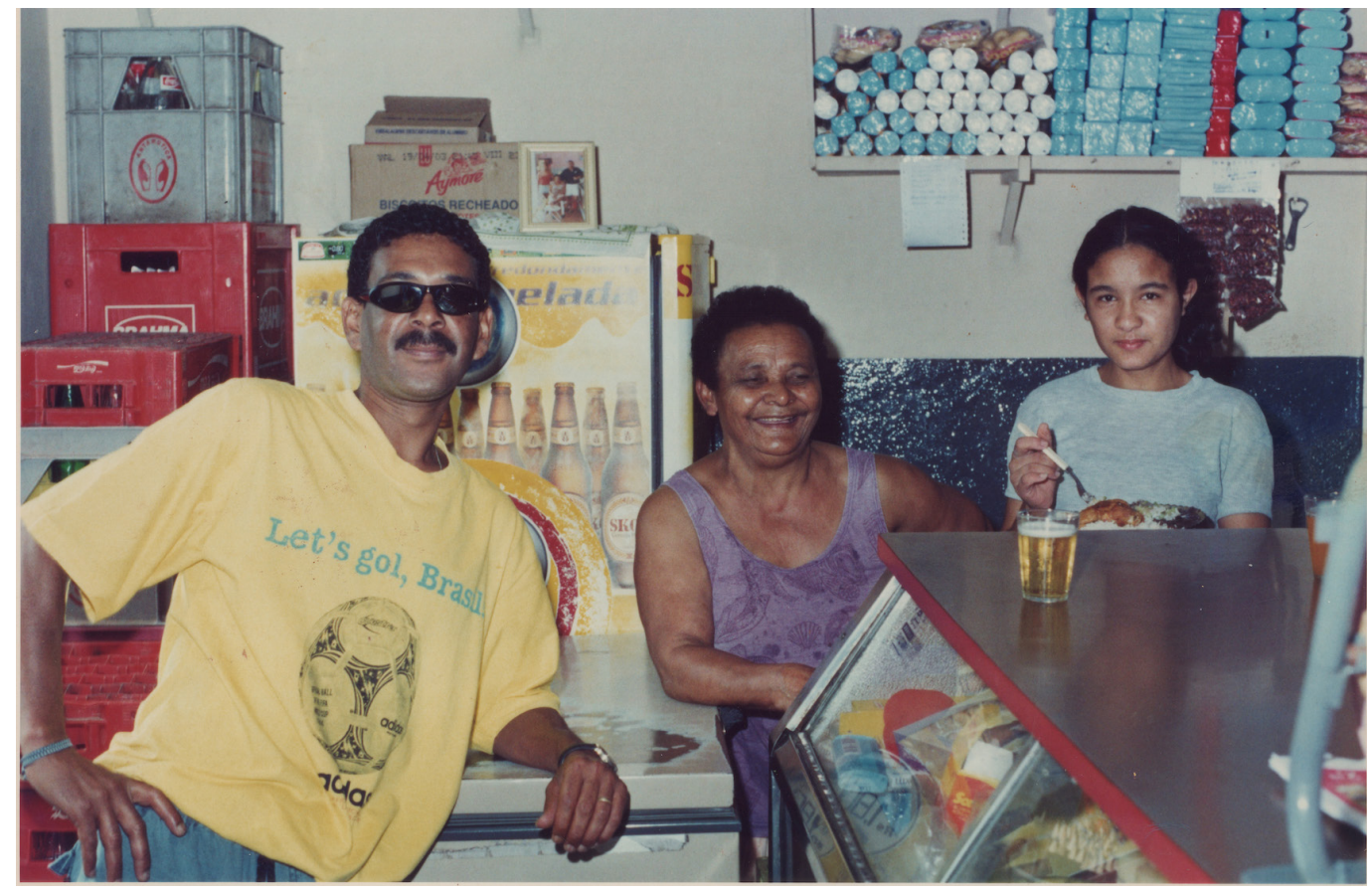

Figura 3. Foto (b) do acervo de Dalva

Fonte: Acervo pessoal de Dalva. Fotografias de Afonso Pimenta digitalizadas pela autora em 2020.

A experiência cotidiana contada nas memórias e fabulações (a respeito de si e da cidade) dessas três mulheres pode contribuir para um entendimento acerca da formação do Aglomerado da Serra e também fornecer pistas sobre uma situação estruturalmente semelhante presente em diversas metrópoles no Brasil.

Eu trabalhei muito. Trabalhei muito desde novinha, né. Aí depois eu vim... Era roça e fazenda que a gente trabalhava. Enquanto eu era nova eu trabalhava na fazenda, cozinheira daqueles fazendeiros lá e depois eu falei assim não aguento esses panelão mais, não. Cozinhei muito! Primeiro a gente trabalhava pra nós, mas quando a situação... a gente vai ficando mocinha a situação vai ficando mais difícil, né. Os velhos vai morrendo, a gente vai ficando mais fraco... e não dava, não rendia nada, aí eu falei assim ah, gente... vamo embora daqui! Aí vim [morar em Belo Horizonte]. [...] Era empregada doméstica, ficava nas casas. Aí eu morava lá com eles, aí depois ela [a patroa] voltou pra lá pra casa e como eu já tava com 18 anos e queria trabalhar pra vestir seda, crepe, esses negócio que eram muito falados, aí eu fiquei por aqui mesmo ${ }^{12}$.

Duas das entrevistadas se mudaram para Belo Horizonte a fim de trabalhar no serviço doméstico terceirizado, em troca de baixa remuneração, abrigo e

12. Entrevista caminhada de Marta, realizada em 2 de junho de 2017. 
alimentação, na casa de pessoas que as trouxeram consigo do interior: falas como "Minha mãe me deu pra um pessoal” indicam um trabalho análogo à escravidão, que às vezes elas suportaram por anos antes de chegarem à Serra.

Na verdade, eu vim pra aqui quando eu tinha cinco anos, que minha mãe me deu pra um pessoal, aí eles morava aqui, aí eu vim morar aqui. Só que depois eles mudaram pro Rio, aí fiquei morando lá... depois eles se mudaram pra outra cidade que se chama Nepomuceno, já ouviu falar? Aí nós fomos morar lá, aí depois fui trabalhar em São Paulo, voltei para Belo Horizonte. Meu destino acho que é aqui mesmo ${ }^{13}$.

Ao desligarmos o gravador, após o término da entrevista caminhada, Irene nos dá detalhes de sua experiência análoga à escravidão. Quando tinha cinco anos de idade, ela e a irmã mais velha foram informalmente "adotadas" por um casal alemão. As duas sofreram diversas formas de violência física e psicológica e eram forçadas a trabalhar em funções domésticas, como o cuidado com os filhos do casal, que eram apenas um pouco mais novos que elas. Quando Irene estava com quinze anos, o casal fez uma viagem e ela planejou sua fuga. A irmã̃, debilitada física e psicologicamente pela violência sofrida, teve medo de ir junto, assim Irene partiu sozinha. Acabou indo morar com parentes distantes em outra cidade. Foi assim que conseguiu se restabelecer minimamente, e, passados alguns anos em trabalhos mais ou menos informais, foi contratada como zeladora em uma fábrica da Fiat, onde trabalhou até se aposentar, anos depois.

Voltar aposentada para Belo Horizonte encerra um ciclo vitorioso em sua trajetória de vida de muito sofrimento, mas também de muita força e resistência. À altura da entrevista, Irene vivia em um apartamento num conjunto habitacional próximo ao Cras Vila Nossa Senhora de Fátima, frequentava aulas de ginástica para idosas regularmente e seu filho, com um emprego fixo, estava noivo e havia recém-comprado um apartamento em frente ao seu, no mesmo prédio e no mesmo andar, para viver com a noiva (Figura 4).

Esse aí é o meu quarto. Eu quando era criança não tive boneca, aí eu falava com meu filho que um dia eu ia comprar uma boneca para mim, aí ele foi um dia e comprou essas bonecas aí pra mim, olha, mãe, já que a senhora não teve infância... aí eu deixei elas lá ${ }^{14}$.

13. Entrevista caminhada de Irene, realizada em 12 de junho de 2017.

14. Diário fotográfico de Irene, realizado em 21 de junho de 2017. 
É comum nos relatos das três mulheres um arco narrativo que tem início com a saída da casa em que nasceram, onde as condições de permanência se tornaram insuportáveis, perpassa a saga de conseguir trabalho e abrigo - é também nesse momento em que acabam experienciando a maternidade - e se encerra em movimentos de superação das dificuldades e conquista de relativa estabilidade material.

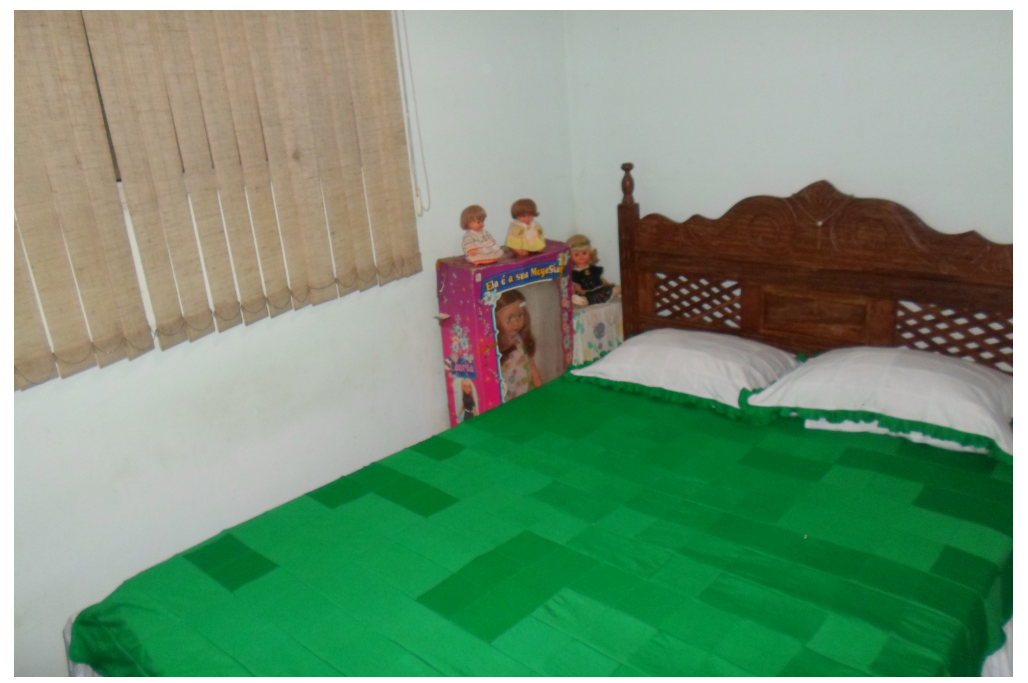

Figura 4. Fotografia do quarto de Irene Fonte: Elaborada pela autora, 2020.

Marta conta que viveu com os filhos em um abrigo mantido pela Igreja Católica por onze anos antes de se mudar para a Serra, onde construiu, com o auxílio de vizinhos, a própria casa.

Eu morava em Santa Efigênia [de Minas], aí quando eu estava com os meninos tudo pequeno, então uma amiga ficô sabendo que ia distribuir os pedaços ali, então eu vim e ganhei um pedaço. Fiquei socorrida do São Vicente de Paulo uns 11 anos, daí eu vim. [...] Eu que construí [a casa], construí primeiro de tábua, tampado com lata, hoje é de alvenaria graças a Deus... A gente não tinha água, não tinha luz, não tinha nada. Graças a Deus hoje tem tudo. E onde eu moro não é muito acidentado, aqui é pior, né? Lá tem mais favorecimento, tem carro perto, rua aberta, tudo direitinho. A situação pra mim hoje... pra mim sair de lá não tem nem como, não tenho vontade, não. Porque carro vai na porta, compra, vai na porta. Um remédio se alguém precisar, é só telefonar. ${ }^{15}$

15. Entrevista estacionada de Marta, realizada em 2 de junho de 2017. 
Devido à baixa remuneração que comumente recebiam, elas acabavam por morar nas bordas da chamada cidade formal, mas nas proximidades dos bairros que concentravam maior renda, na Região Centro-Sul de Belo Horizonte, onde havia melhores oportunidades de empregos. Morar em uma ocupação urbana ainda pouco consolidada implicava muitos desafios na vida cotidiana daquelas mulheres, desde algo tão trivial, como andar na terra e na lama, e ter que chegar de pés imaculados a um destino onde "ser limpa" é requisito de acesso. Àquela altura, os suprimentos mais básicos, como água, lenha ou gás, a lavagem e o conserto de roupas e o preparo dos alimentos, eram providos pelas mulheres, ao lado de outras funções desempenhadas por elas, como acompanhar crianças e outros familiares em longas caminhadas pelo mato até um posto de atendimento médico, por exemplo.

De dia eu trabalhava com eles [uma ONG estrangeira] e de noite eu tomava conta de uma senhora. Três da manhã eu tava lavando roupa, fazendo a comidinha pra deixar pro meus filhos, pra mim trabalhar. Era três crianças que eu tinha. Eu deitava, na hora que eu dormia, que eu acordava, tava chovendo, a água tava entrando dentro do barracãozinho. Pegava enxada e um plástico, botava na cabeça, meia-noite, uma hora da manhã e eu dentro da lama, do esgoto. [...] Aqui nesse tempo não tinha leite. Morria muito menino de fome. É porque não tinha o que comer ${ }^{16}$.

Quando eu vim pra aqui nós lavava roupa aqui. Eu moro lá em cima, lá em cima. Aí nós descia e vinha lavar roupa aqui. Tinha água e caía essa água do canão que passava aqui. Levava a água lá pra cima. Levava roupa seca e água, lá pra cima, subia. [...] A gente cozinhava com lenha. E o gás, a gente tinha o gás era uma vez no mês, que ele vinha, né, aí as vezes acabava no fim do mês... Eu se valia, que às vezes eu buscava gás para os outros para ganhar vinte centavos. [...] Aí a gente buscava o gás, eu buscava pros outros, porque eu tinha muita força, né? ${ }^{17}$

Outro aspecto particular da experiência dessas mulheres periféricas e racializadas é relativo à permanência do trabalho de cuidado no decorrer de suas vidas. Ao contrário do imaginário de ócio construído sobre pessoas idosas, as moradoras da Serra seguem ao longo de toda a vida, em alguma medida, responsáveis pelo trabalho de cuidado com as diferentes gerações posteriores.

É emblemático dessa conjuntura o relato de Marta, que, abandonada pelo pai de seus filhos, os criou sozinha. Ela conta da morte prematura de uma filha que

\footnotetext{
16. Entrevista estacionada de Dalva, realizada em 5 de junho de 2017.
}

17. Entrevista caminhada de Marta, realizada em 2 de junho de 2017. 
deixou quatro filhos, também criados por ela. E à altura da entrevista, aos 82 anos, Marta ainda cuidava de um bisneto.

Ih, minha filha! Moro, moro com neto, porque filho casou e mora em cima, neto mora comigo. Mora três, quatro netos. [...] Meu neto mais novo tá com 23, já tem dois filhos. São todos velhos, mas sempre sobra pra gente, né, tô cuidando ainda. Cuidei dos filhos. Tive uma filha, ela morreu cedo, com trinta anos, deixou quatro filhos, criei os quatro filhos, casei três, já casei três dos filhos... Dia 14 vai ter o casamento do meu que vai naquela comunitária do Mineirinho. Casamento comunitário. A menina casou, depois juntou, casou a cunhada dela, agora vai casar o irmão. Aí a gente vai fazer uma reuniãozinha pra ele lá. Às vezes pego o ônibus, eu vou, fico um pouquinho no Parque Municipal, do parque vou pra igreja São José, fico lá e volto com a cabeça boa. Porque eu tento ficar com a cabeça boa, que é muita coisa pra eu olhar. Então, eu acho que eu tenho que cuidar de mim, que eu nunca tive ninguém pra me cuidar. E é isso, os meninos, eles não vão cuidar, então quando tá apertando, eu dou uma saidinha, aí quando eu volto, eu volto legal.

Domingo mesmo eu tava uma... porque eu tenho um neto que não é muito... que às vezes faz as coisas que eu não gosto, mas eu não sou de ficar falando, nem de ficar brigando, ficar xingando, né. Aí eu tava ruim e falei meu pai, o que eu faço? Aí a menina falou assim, na hora que eu estava descendo ih, na sua casa tá cheio de gente... E era gente que eu não gosto. Então eu falei meu pai, ir lá pra ficar olhando pra cara daquele povo... [...] aí eu fui, peguei o ônibus, fui embora lá para a cidade, fui pro parque, cheguei no parque, mas fiquei triste quando cheguei no parque. Tinha muito tempo que eu não ia no parque. Fiquei triste, muito mendigo, malcheiroso.

Eu fiquei assim, mas cheguei, sentei e fiquei com a mão assim, veio um casalzinho assim, novinho, assim como se fosse vocề... oh, senhorinha, tá passando mal? E eu falei tô não, meu filho, que eu tava nervosa, né. É que eu vou lá pra chorar, quando as vezes tá demais, eu vou pra chorar. [...] Aí saiu, aí saí dali, fui pra igreja São José, assisti a missa, andei um cadinho, fui até na rua... perto da rua Tupis, voltei, aí quando foi seis horas, que eu cheguei em casa, eles já tinham ido embora, aí eu fui fazer minhas coisas. Aí cheguei no lugar, entendeu? Agora eu tenho um negócio, quando às vezes... porque sempre eu venho no psicólogo, converso com a psicóloga, porque eu não posso. Porque eu sou uma pessoa assim... Eu sozinha, eu sozinha pra resolver tudo. Eu criei cinco filhos, com mais quatro da minha filha, nove. E já casei meus filhos tudo, já casei os netos, agora os bisnetos ficam rodeando e ficam fazendo coisas que eu não tô aguentando... que eu não tô gostando, aí eu saio. Saio um pouquinho, vou. Aí alenta, aí eu venho embora, porque eu tenho medo de ficar batendo de frente 
com ele e eu não tô mais na época de bater de frente com ninguém. Eu não tô. E aí, graças a Deus, vou controlando. ${ }^{18}$

\section{Inferências preliminares}

Diante do exposto, é possível indicar a ficção como uma categoria importante para questionar a dominação dos discursos oficiais, articulados prioritariamente por meio do texto escrito, nas pesquisas sócio-espaciais e nas narrativas sobre as cidades, de maneira geral.

Os relatos das moradoras idosas do Aglomerado da Serra, aqui estudados, carregam consigo uma série de informações valiosas sobre a formação desse território específico, mas apontam também aspectos estruturais presentes em uma variedade de contextos urbanos no Brasil contemporâneo. Esses relatos, historicamente, suprimidos dos discursos oficiais sobre as cidades, adicionam elementos de imensa relevância para a complexificação do modo como a academia tem tradicionalmente abordado a vida nas periferias urbanas. Entender e narrar esses modos de vida representa um desafio nos campos da imaginação e da linguagem, porém

é, sobretudo para a academia, um desafio intrinsecamente metodológico. É preciso desprogramar as formas de pensar e descrever o mundo fundadas nas maneiras de conhecer modernas, para que seja possível imaginar ou mesmo enxergar outros mundos possíveis - muitos dos quais já existem.

É nesse sentido que sugiro a ficção como ferramenta metodológica potencialmente adequada para lidar com grupos sócio-espaciais urbanos cujas vivências passam ao largo das lógicas formais de produção do espaço. Partindo da experiência de entrevistar essas mulheres, a ficção como estratégia metodológica encontra lugar precisamente nos silêncios de suas falas e na ausência de ferramentas no discurso institucional tradicional sobre o espaço para perceber o que aí se produz como potência.

A ficção aqui é entendida não como gênero narrativo que se contrapõe ao documental, e sim como qualidade própria de toda narrativa. Considerando que as narrativas são representações ou abstrações dos acontecimentos, há nelas um grau de imprecisão inerente em relação ao que seria a realidade objetiva.

Sugiro ainda a imagem e a oralidade como dispositivos possíveis para articular a ficção nesse contexto, no qual há o encontro de interlocutoras acadêmicas, cujo texto escrito é a principal forma de articulação do pensamento, com interlocutoras que tiveram pouco ou nenhum acesso à escolarização formal, as quais, portanto, articulam o conhecimento sem o recurso à palavra escrita.

18. Entrevista estacionada de Marta, realizada em 2 de junho de 2017. 
Imagem e oralidade são duas modalidades comunicacionais que podem estar articuladas ao texto escrito, mas que não dependem fundamentalmente dele para existir. Podem, assim, transitar à margem do texto e, em última instância, à margem do conhecimento acadêmico - considerado prioritariamente legítimo na sociedade moderna ocidental.

A ficção articulada por meio da imagem e da oralidade pode, por um lado, mobilizar a relativização daquilo que conhecemos como saber legítimo e como história oficial e, por outro, servir como ferramenta de especulação sobre outros mundos possíveis.

\section{Referências}

DE CERTEAU, M. A escrita da história. Rio de Janeiro: Forense universitária, 1982.

FERREIRA DA SILVA, D. Sobre diferença sem separabilidade. In: BIENAL DE SÃO PAULO. Incerteza viva: catálogo. São Paulo, 2016. Catálogo da exposição Incerteza viva da Bienal de São Paulo, 7 de setembro a 11 de dezembro de 2016. p. 57- 63. Disponível em: http:// www.bienal.org.br/publicacoes/3325. Acesso em: 2 dez. 2019.

. A dívida impagável. São Paulo: Casa do Povo, 2019.

FLUSSER, V. A filosofia da caixa-preta: ensaios para uma futura filosofia da fotografia. São Paulo: Hucitec, 1985.

Line and surface. In: STRÖHL, A. [ed.]. Writings, Vilém Flusser. Minnesota: University of Minnesota Press, 2002.

HARTMAN, S. Wayward lives, beautiful experiments: intimate stories of social upheaval. New York: W. W. Norton \& Company, 2019. E-book.

IMARISHA, W. Reescrevendo o futuro. Tradução: Jota Mombaça. 2016. [online]. Disponível em: https://issuu.com/amilcarpacker/docs/walidah_imarisha_reescrevendo_o_fut. Acesso em: 17 set. 2019.

MARTINS, L. M. Performances da oralitura - corpo lugar e memória. Revista do programa de pós-graduação em Letras, Santa Maria, p. 63-81, 2003.

MBEMBE, A. The Power of Archive and Its Limits. In: HAMILTON, C.; HARRIS, V. et al. (ed.). Refiguring the archive. Cape Town: Alyson Printers, 2002. p. 19-26.

NORA, P. Entre memória e história: a problemática dos lugares. Projeto História - Revista do programa de estudos pós-graduados de História, São Paulo: PUC, 1993. p. 7-28.

PEREIRA, G. L. Corpo, discurso e território: a cidade em disputa nas dobras da narrativa de Carolina Maria de Jesus. 2015. Tese (Doutorado em Arquitetura e Urbanismo) Universidade Federal da Bahia, Faculdade de Arquitetura, Salvador, 2015. 252 p.

SANDERCOCK, L. Debatendo o preconceito: a importância das histórias e de sua narração na prática do planejamento. Cadernos IPPUR, ano XIX, n. 1 e 2, p. 289-315, jan.-dez. 2005.

TAYLOR, D. O arquivo e o repertório. Belo Horizonte: Editora da UFMG, 2013. 


\section{Camila Matos Fontenele}

Graduada em Arquitetura e Urbanismo pela Universidade Federal do Ceará (UFC). Mestre em 2016 pela Universidade de Minas Gerais (UFMG) e doutoranda no Programa de Pós-graduação em Arquitetura e Urbanismo da mesma instituição. Atualmente, é pesquisadora assistente no grupo Morar de Outras Maneiras (MOM) da Escola de Arquitetura da UFMG.

Email: camilamatosf@gmail.com

ORCID: 0000-0003-2526-2296

Submissão: 20 de dezembro de 2020.

Aprovação: 8 de agosto de 2021.

Como citar: MATOS FONTENELE, C. Narrar a Serra, imaginar as cidades: o recurso à ficção na pesquisa sócio-espacial. Revista brasileira de estudos urbanos e regionais. Dossiê Território, Gênero e Interseccionalidades. v. 23, E202134, 2021. DOI 10.22296/2317-1529. rbeur.202134

Artigo licenciado sob Licença Creative Commons CC BY 4.0.

https://creativecommons.org/licenses/by/4.o/deed.pt_BR 